\title{
Calcium, Network Activity, and the Role of NMDA Channels in Synaptic Plasticity in vitro
}

\author{
R. Douglas Fields, Chang Yu, and Phillip G. Nelson \\ National Institutes of Health, NICHD, Laboratory of Developmental Neurobiology, Bethesda, Maryland 20892
}

Functionally effective neuronal circuits are constructed through a competitive process that requires patterned neuronal activity elicited by structured input from the environment. To explore the mechanisms of this activity-dependent synaptic restructuring, we have developed an in vitro preparation of mouse spinal cord neurons maintained in a 3-chambered cell-culture system. Sensory afferents that received chronic electrical stimulation for 3-5 d developed stronger synaptic connections than unstimulated afferents converging onto the same postsynaptic spinal cord neuron. Exposure to $100 \mu \mathrm{M}$ DL-2-amino-5-phosphonovaleric acid (APV), an antagonist of the NMDA channel, during the stimulation period prevented the competitive advantage associated with electric stimulation. However, when APV was applied with a higher concentration of calcium (3 $\mathrm{mm}$ ), activity-dependent synaptic plasticity was no longer inhibited by the NMDA receptor antagonist. This reversal of APV block of the plasticity was not impaired by reducing transmitter release with $3 \mathrm{~mm}$ magnesium (in addition to $3 \mathrm{~mm}$ calcium and APV).

A suppressant effect of APV on spontaneous activity was observed, which was attributed to loss of the NMDA component of the EPSP. Activity-dependent plasticity was also blocked if spontaneous activity was suppressed with dilute tetrodotoxin (TTX; 5-10 nM), a dosage that reduces excitability of neurons but is insufficient to block sodium-dependent action potentials.

These experiments bring into question how NMDA channel activation is involved in the processes of synaptic remodeling during development. The data suggest that postsynaptic activity is required for synaptic remodeling, but this activity need not involve NMDA receptor activation specifically for activity-evoked synaptic plasticity. Instead, the mechanism for plasticity appears to operate through calcium-dependent processes in general.

Synaptic connections are formed and strengthened, weakened and broken in a pattern imposed in part by electrical activity in developing neural circuits. Another form of synaptic modification is the long-term potentiation (LTP) of EPSP amplitude initiated by high-frequency stimulation in the adult hippocam-

\footnotetext{
Received Mar. 14, 1990; revised Aug. 16, 1990; accepted Aug. 31, 1990.

We thank Sandra Fitzgerald for assistance with tissue culture and David Lange for helpful discussions.

Correspondence should be addressed to R. Douglas Fields, Ph.D., National Institutes of Health, NICHD, Laboratory of Developmental Neurobiology, Building 36, Room 2A21, Bethesda, MD 20892.

Copyright (C) 1991 Society for Neuroscience $0270-6474 / 91 / 010134-13 \$ 03.00 / 0$
}

pus. The mechanism for this synaptic enhancement is incompletely understood and controversial (cf. reviews by Nicoll et al., 1988; Wickens, 1988); however, activation of NMDA channels has been implicated in the initiation phase of LTP in some hippocampal regions (Collingridge et al., 1983; Harris et al., 1984; Morris et al., 1986; Collingridge and Bliss, 1987; Larson and Lynch, 1988) and in the mammalian visual cortex (Artola and Singer, 1987) and goldfish optic tectum (Schmidt, 1990). The resemblance between these 2 forms of synaptic plasticity raises the question of whether NMDA-dependent LTP and synaptic restructuring during development share a common cellular mechanism.

NMDA channel activation has been implicated in the developmental processes of synaptic restructuring by the demonstration of impaired activity-dependent synaptic segregation of axon terminals in the visual system under conditions of NMDA receptor blockade (Cline et al., 1987; Kleinschmidt et al., 1987; Cline and Constantine-Paton, 1989; Gu et al., 1989; Scherer and Udin 1989; Debski et al., 1990). We wished to investigate the premise that NMDA channel activation is necessary for activity-dependent synaptic plasticity in neurons having these receptors. The results of this study and previous results (Nelson et al., 1990) show that this premise is not valid. In addition, these experiments provide evidence that an essential requirement for activity-dependent synaptic plasticity relates to calcium influx into the postsynaptic neuron. While influx of calcium through the NMDA channel is one means to this end, NMDA channel activation does not constitute a sufficient or necessary condition for plasticity in this in vitro preparation of spinal cord neurons.

Four factors that are important in activity-dependent synaptic plasticity have been identified through studies on many different types of neurons: (1) the amount and pattern of afferent stimulation (Wiesel and Hubel, 1963, 1965; Martin et al., 1979; Le Vay et al., 1980; Rauschecker and Singer, 1981; Archer et al., 1982; Schmidt and Edwards, 1983; Fawcett and O'Leary, 1985; Dubin et al., 1986; Magchielse and Meeter, 1986; Stryker and Harris, 1986; Callaway et al., 1989), (2) postsynaptic activation (Thompson, 1983; Wigstrom and Gustafsson, 1985; Kelso et al., 1986; Malinow and Miller, 1986; Wigstrom et al., 1986; Reiter and Stryker, 1988), (3) calcium influx (Dunwiddie and Lynch, 1979; Wigstrom et al., 1979; Baimbridge and Miller, 1981; Eccles, 1983; Lynch et al., 1983; Lynch and Baudry, 1984; Malinow and Miller, 1986; Izumi et al., 1987; Swanson and Vrbová, 1987; Malenka et al., 1988), (4) $N M D A$ receptor activation in neurons with these receptors. Unfortunately, all 4 factors are tightly interlinked, making it difficult to isolate the relative significance of each factor in the process leading to modification in strength or number of synaptic connections in 


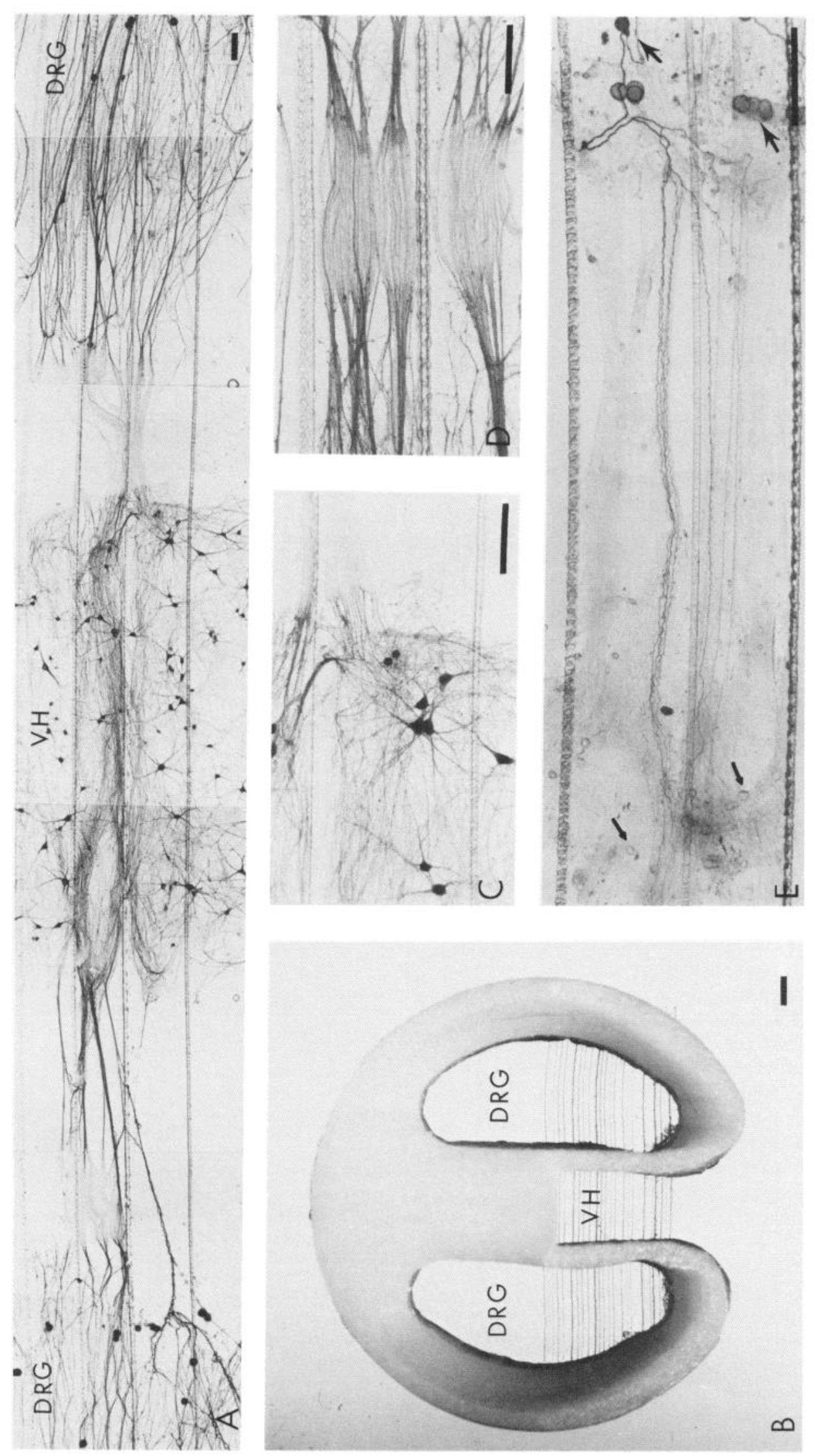

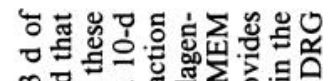

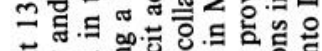

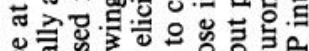

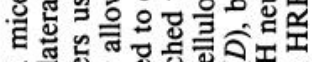

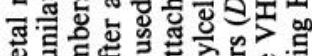

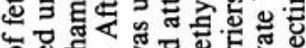

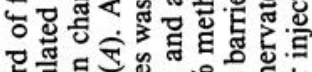
뭉혈.

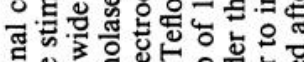

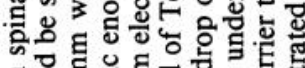

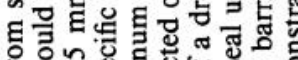

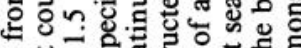

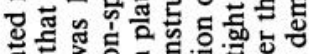

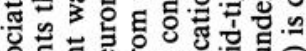

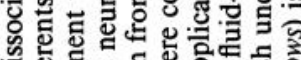

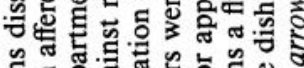

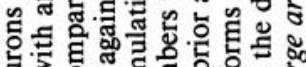

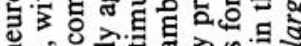

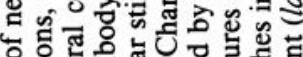

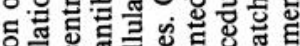

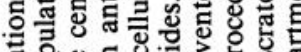

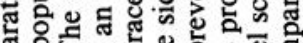

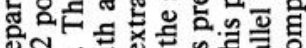

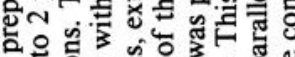

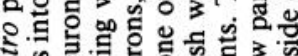

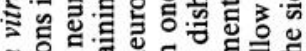
इ 两 ธ

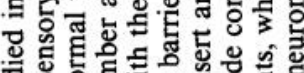

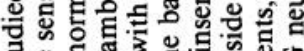
造过

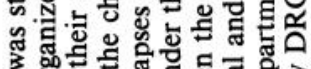

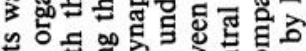

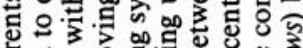

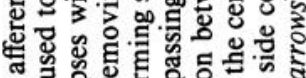
击

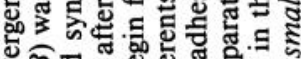

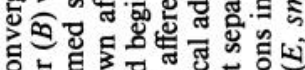

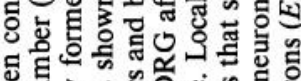

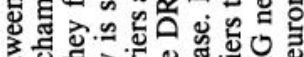

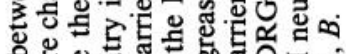

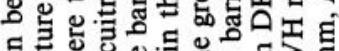

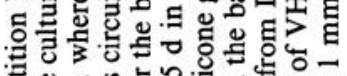

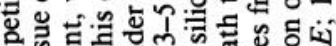

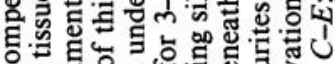

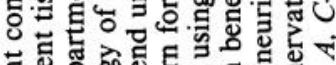

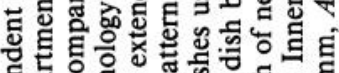
댕영영

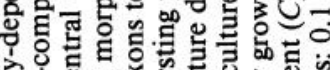

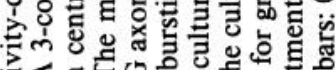

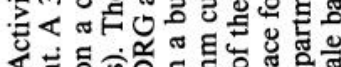

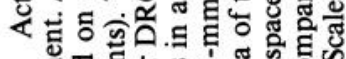
一

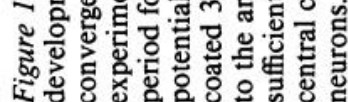




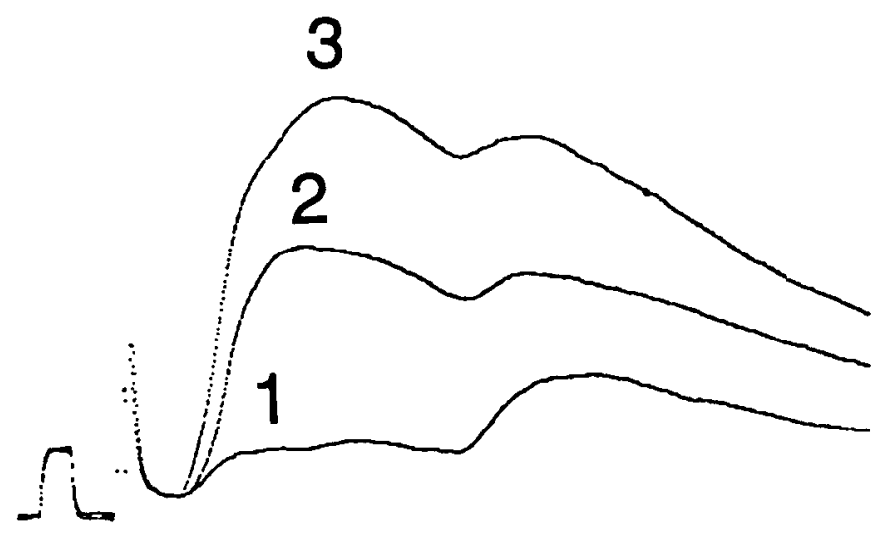

Figure 2. Intracellular recording of EPSPs from VH neuron in central compartment of 3-compartment culture chamber, in response to stimulating action potentials in DRG afferents from one side compartment. Three superimposed responses (each averaged 5 times) to afferent stimulation at different intensities of stimulation demonstrate the method by which the number of functional inputs to each VH neuron was estimated from each side compartment. In this neuron, gradually in creasing the stimulation intensity resulted in 3 discrete responses representing at least 3 functional inputs from this side compartment that differ slightly in their threshold to stimulation (Redfern, 1970). The amplitude of the peak and lowest-threshold monosynaptic component were recorded. The longer latency peaks (greater than $15 \mathrm{msec}$ ) represent polysynaptic inputs that were not analyzed. All recordings were made in $3 \mathrm{mM} \mathrm{Ca}^{2+}, 3 \mathrm{mM} \mathrm{Mg}^{2+}$ and $5 \mathrm{nM}$ TTX to reduce action potentials and polysynaptic responses. Calibration pulse: $2 \mathrm{msec}, 2 \mathrm{mV}$.

a functional neuronal circuit. For example, the NMDA receptor antagonist DL-2-amino-5-phosphonovaleric acid (APV) will suppress not only NMDA channel activation, but calcium influx into the postsynaptic neuron, and postsynaptic activity via inhibition of polysynaptic connections with the postsynaptic neuron (Fox and Armstrong-James, 1986; Fox et al., 1989; Miller et al., 1989; Brenneman et al., 1990a,b) and reduce monosynaptic EPSP amplitude to a variable extent (Tsumoto et al., 1987; Forsythe and Westbrook, 1988; Fox et al., 1989; Ziskind-Conhaim, 1990). These interactions are difficult to isolate and control in intact preparations, but a high degree of control is afforded by reconstructing the circuit in vitro from neurons dissociated from the CNS of fetal animals. We have used such a preparation derived from neurons dissociated from the spinal cord and dorsal root ganglia (DRG) of mice and organized in a multicompartmented cell-culture chamber. A bilaterally symmetrical design enables selective stimulation of one population of afferents that converge with unstimulated afferents onto the same postsynaptic neuron (Nelson et al., 1989a). Electrophysiological recording methods can be used to assess changes in synaptic strength or number of functional neuronal contacts from the 2 sets of convergent afferents.

A general theory originating from studies of associative learning and conditioning, and further articulated by Hebb (1949), proposes that the coincidence of activation between an afferent and sufficient activation of the postsynaptic neuron provides the logical condition for initiating an increase in the efficacy of the connection. Dissonant firing of an afferent and the postsynaptic neuron should promote the weakening of the afferent (Stent, 1973). What constitutes an "adequate level" of postsynaptic activity is unknown. It might be the threshold for action-potential generation reached by the near-simultaneous firing of a sufficient number of excitatory afferents, or a sufficient elevation in intracellular calcium $\left(\left[\mathrm{Ca}^{2+}\right]_{i}\right)$, or depolarization of the post- synaptic membrane to a level that permits activation of NMDA channels, or some other critical level of depolarization. [It, is, however, known that generation of action potentials in the postsynaptic neuron is not necessary for LTP (Kelso et al., 1986; Wigstrom et al., 1986)].

In the present experiments, the level of postsynaptic activity was manipulated independently of activity provided by afferent input, by suppressing spontaneous activity in the network of spinal cord neurons that contribute activity to the postsynaptic target. This was accomplished by suppressing the excitability of spinal cord neurons with a dilute concentration of tetrodotoxin (TTX; 5-10 nM; with or without elevating divalent cations), a treatment that increases the failure of polysynaptic connections, but leaves monosynaptic afferent inputs and the axon of the postsynaptic neuron free to respond to stimulation (Berry and Penreath, 1976; King et al., 1989). The importance of calcium was investigated by elevating the concentration of calcium in the extracellular medium to $3 \mathrm{~mm}$ from a normal value of 1.8 mM. The involvement of NMDA channels was studied by using the competitive antagonist APV to block NMDA channel activation (Watkins and Evans, 1981). The role of disparity in electrical activity of afferents converging onto the same postsynaptic neuron was studied by providing patterned electrical stimulation to 1 of 2 sets of convergent afferents.

Portions of this study have been reported previously (Fields et al., 1989; Nelson et al., 1989b, 1990).

\section{Materials and Methods}

Cell culture. Teflon inserts were attached with silicone grease to collagencoated 35-mm culture dishes to form chambers with 3 compartments (Campenot, 1977). The inserts were machined from 4-mm-thick Teflon disks to provide 2 bilaterally symmetrical compartments flanking a central notch-shaped compartment (Fig. 1). A series of shallow parallel scratches were made in the bottom of each dish, and a drop of $1 \%$ methylcellulose in Eagle's minimum essential medium (MEM) was applied to this area before assembly. This procedure forms a fluid-tight seal under the barrier but provides sufficient space for the growth of neurites from DRG neurons in the side compartments to innervate ventral horn (VH) neurons in the central compartment.

Neurons from the spinal cord were dissociated from 13-d mouse fetuses, and cortical glia and support cells were dissociated from the cortex of newborn mice (see Nelson et al., 1989a, 1990). Neurons from $\mathrm{VH}$ of the spinal cord were dissociated and plated into the central compartment on a confluent layer of non-neuronal cortical cells plated 1 week previously. These neurons were maintained in medium containing $5 \%$ horse serum and $15 \mathrm{ng} / \mathrm{ml} \mathrm{NGF}$. Neurons were dissociated from the DRG of the same spinal cords and plated into the side compartments in medium containing $30 \mathrm{ng} / \mathrm{ml}$ NGF. Mitosis was inhibited after $2 \mathrm{~d}$ by the addition of $13 \mu \mathrm{g} / \mathrm{ml}$ fluoro-2'-deoxyuridine. After 1 week, DRG neurons begin extending axons under the barrier and forming synapses with the VH neurons. VH neurons are not able to extend axons or dendrites under the barrier.

This procedure is modified from Nelson et al. (1989a), where DRG neurons were plated 1 week after the VH neurons. The amplitude of the EPSPs tended to be smaller in the younger VH neurons, but synaptic strength was more uniform across the central compartment.

Chronic stimulation. Nine to $12 \mathrm{~d}$ after plating the DRG neurons, one of the side compartments in each culture was stimulated electrically for a period of 3-5 d. Stimulation was provided through 3-extracellular platinum electrodes fitted into the lid of the culture dishes. Current pulses were passed between an electrode in one of the side compartments, and a remote electrode in the medium surrounding the insert and in continuity with the central compartment. A constant-voltage pulse generator was used to deliver a train of 5 stimuli at $10 \mathrm{~Hz}$, repeated every 2 sec. Each stimulus was comprised of 2 biphasic pulses of 200$\mu \mathrm{sec}$ duration, $6 \mathrm{~V}$ amplitude, and separated by $5 \mathrm{msec}$. The adequacy of stimulation was confirmed by recording responses in VH neurons in preparations stimulated in parallel with those in the incubator. This stimulation excites preferentially those neurons with axons under the 
barrier. The intensity of stimulation is $2-3$ times the threshold for action potential generation in DRG neurons. A minority (ca. 5\%) of VH neurons were also antidromically activated by stimulation (Nelson et al., 1989a; Neale et al., 1990).

Electrophysiological recording. Three to $5 \mathrm{~d}$ after stimulation, microelectrodes or patch electrodes were used to record EPSPs in VH neurons in response to DRG stimulation (Fig. 2). DRG inputs from each side compartment were stimulated in turn, and the strength and number of functional inputs were quantified. Recordings were carried out in HEPESbuffered medium ( $\mathrm{pH}, 7.4$ ) containing $3 \mathrm{mM} \mathrm{Ca}^{2+}, 3 \mathrm{mM} \mathrm{Mg} \mathrm{Mg}^{2+}$, and 5 nM TTX to suppress action potentials and reduce polysynaptic activity. If action potentials were encountered, they were blocked by hyperpolarization. Hyperpolarizing and depolarizing currents were injected into the cell to differentiate unambiguously EPSPs from possible IPSPs, and active orthodromic and antidromic conductances. Recordings were rejected from any cells where these methods failed to differentiate the EPSP unambiguously for both afferent inputs. The hyperpolarizing current was generally held constant during measurements of the maximum EPSP amplitude from the 2 sides, but in some cases, amplitudes were determined with hyperpolarizing currents just sufficient to block any spikes that occurred from either side; either of these procedures provides an index of the relative synaptic strength of the afferent connection. The peak amplitude of the monosynaptic component of the EPSP was recorded in response to stimulating each side. (Data were recorded from only 1 input in 3 cells: 2 from the stimulated side and 1 from the unstimulated side in medium 1 of Table 1. Excluding these values did not materially affect the results, and they have been included for completeness.) The polysynaptic component of the EPSP, when present, was distinguished by its variable and longer latency (greater than $15 \mathrm{msec}$ ). The number of functional inputs was determined by gradually increasing the strength of stimulation to recruit afferents sequentially according to differences in threshold of excitability (Fig. 2; Redfern, 1970; Nelson et al., 1989a, 1990). The amplitude of the lowest threshold input was also recorded to assess changes in strength of unitary inputs.

Experimental design. NMDA channel activation was blocked by including DL-APV $(100 \mu \mathrm{M})$ in the central compartment at the time of stimulation. Spontaneous activity in the network of ventral horn neurons was suppressed in some cultures by adding $5 \mathrm{nM}$ tetrodotoxin (TTX) and increasing the $\mathrm{Mg}^{2+}$ and $\mathrm{Ca}^{2+}$ concentration of the medium to 3 mM each to reduce the excitability of axons. This network-suppression medium was added at the time of stimulation, and recordings showed that it did not lower excitability sufficiently to block monosynaptic or electrically evoked connections. The effect of APV treatment was tested in both normal medium and medium with elevated calcium or reduced network activity.

A high dosage of APV was chosen for these experiments to assure complete blockade of the NMDA receptor during the period of chronic stimulation. The dosage of $100 \mu \mathrm{M}$ DL-APV is within the range used in other studies to demonstrate the dependence of various forms of synaptic plasticity on NMDA channel activation (e.g., Harris et al., 1984; Morris et al., 1986; Cline et al., 1987; Kleinschmidt et al., 1987; Larson and Lynch, 1988; Muller et al., 1988; Gu et al., 1989). As a test for nonspecific effects of the drug at this concentration, changes in EPSP amplitude were measured in paired intracellular recordings during 100 $\mu \mathrm{M}$ APV perfusion. This confirmed the efficacy of the drug in eliminating the NMDA component of the EPSP in medium with normal and $3 \mathrm{~mm}$ $\mathrm{Ca}^{2+}$. These measurements failed to provide any evidence for presynaptic effects of the APV (cf. Collingridge and Lester, 1989), such as reduction in transmitter output or change in the non-NMDA component of the EPSP. Peak amplitudes of the EPSP were not significantly different before and after perfusing $100 \mu \mathrm{M}$ APV in tests of 7 pairs of cells (mean change in amplitude $=0.41 \mathrm{mV}$ increase after APV perfusion, which was not significant by a paired $t$ test).

To randomize variation associated with the experimental preparation (e.g., the dissection and plating technique, amount of axonal outgrowth under the barriers, and spatial factors), data were pooled from multiple preparations made from different dissections over a period of several weeks or months. Usually, the results from about 4 dissections were pooled for any given treatment. In all but one experiment [medium 4 (see Table 1)], recordings were made by two observers independently and their results were pooled.

There is a weak correlation between EPSP amplitude and length of the afferent fiber from the barrier to the $\mathrm{VH}$ neuron: coefficient of determination $\left(r^{2}\right)=0.046$ for all data pooled; slope $=-0.63 \mathrm{mV} / 100$ $\mu \mathrm{m}(n=493)$. To avoid a bias due to location effects, it is important that spinal cord neurons are selected for intracellular recording from random locations in the central compartment. $\mathrm{A} \chi^{2}$ test failed to detect any difference in the number of recordings from afferents ipsilateral and contralateral to the stimulated barrier in any experimental group. As a further check, if a linear regression of EPSP amplitude and VH location is applied to correct for possible error in measurements of mean EPSP amplitude due to spatial effects (using the slope of the regression times the mean difference in distance between stimulated and unstimulated afferents in each medium), the statistical significance of the results are not changed. The slopes of the regression of EPSP amplitude and distance of the VH from the barrier ranged from $-0.3 \mathrm{mV} / 100 \mu \mathrm{m}$ (not significantly different from 0 ) to $-1 \mathrm{mV} / 100 \mu \mathrm{m}$ in treatments $1,2,3$ 4 , and 6 (of Table 1); $r^{2}=0.003-0.193$. In media 5 and 7 of Table 1 , the length of the convergent afferents was not measured in each recording, but the number of ipsilateral and contralateral stimulated afferents were not significantly different.

The bilaterally symmetrical design of the multi-compartmented culture dish provides the necessary control for comparing the effects of different media on the activity-induced plasticity between afferents converging onto the same postsynaptic neuron. According to this design, plasticity is considered a significant difference in EPSP amplitude or number for the stimulated convergent afferent. The absolute number or strength of EPSPs from the stimulated or unstimulated afferents in different experiments would be subject to additional sources of variation, and such cross-experimental comparisons must be made with more caution. In testing the effects of any given treatment on the activityinduced synaptic plasticity, the different media were distributed as evenly as possible from among 6-10 culture dishes from each dissection. Experiments were carried out in 3 such balanced experiments: Experiment 1 , normal medium, medium containing $3 \mathrm{~mm} \mathrm{Ca}^{2+}, 3 \mathrm{~mm} \mathrm{Mg}^{2+}$, and 5 nM TTX, and these 2 media supplemented with $100 \mu \mathrm{M} \mathrm{APV}$ Experiment 2, medium containing $3 \mathrm{mM} \mathrm{Ca}^{2+}$, with and without APV; Experiment 3, medium containing $10 \mathrm{nM}$ TTX, with and without APV.

Statistical analysis. The distribution of EPSP amplitudes is skewed to the right; therefore, a nonparametric method of statistical analysis was used to test the hypothesis that there was no difference in amplitude of EPSPs from the pairs of afferents to $\mathrm{VH}$ neurons after stimulating the afferents from one side for 3-5 d. The Mann-Whitney $U$ test was chosen because it is based on differences in ranked values and is therefore not biased by excessively large EPSP amplitudes nor non-normality of EPSP distributions. In a separate analysis, the amplitude of the EPSP from the stimulated afferent was subtracted from the amplitude of the unstimulated afferent for each intracellular recording to obtain the mcan difference in EPSP amplitude in each experimental medium. The hypothesis that these differences were not greater than 0 (i.e., that the EPSPs were not larger on the stimulated side) was tested with a $t$ test because the distribution of these differences was normally distributed. Media in which the results of this test were not statistically significant were considered to have blocked the activity-dependent plasticity. The number of functional inputs were also analyzed by the Mann-Whitney $U$ test because these are discontinuous ordinal variables. The Kruskal Wallace nonparametric test was applied for multiple group comparisons. In Experiment 1 (described above) a 3-way analysis of variance (ANOVA) of EPSP amplitudes $(N=387)$ and an analogous nonparametric multifactorial partitioning of variance procedure on the number of functional inputs (Winer, 1971) were used to determine the main factors affecting synaptic strength (comparing treatment with chronic stimulation, APV, and medium with $3 \mathrm{mM} \mathrm{Ca}{ }^{2+}, 3 \mathrm{mM} \mathrm{Mg}^{2+}$, and $5 \mathrm{nM}$ TTX) and any significant interactions among these treatments. Calculations for data analysis were performed with the assistance of the computer programs MINITAB (Minitab Inc.), CRUNCH (Crunch Software Corp.), and NCSS (Pacific Ease Co.).

Both the mean and median EPSP amplitudes were calculated. In our opinion, the mean is a better indicator of central tendency of the distributions of EPSP amplitudes, because the electrophysiological response of the postsynaptic neuron is a summation of EPSP amplitudes, and thus, the mean has more biological relevance than the median.

\section{Results}

\section{Electrophysiological properties of the in vitro preparation}

Intracellular recordings from spinal cord neurons in the central compartment showed considerable spontaneous activity that was characterized by periodic bursts of action potentials (Fig. $3 A, E)$. DRG neurons lacked spontaneous activity, but respond- 
A

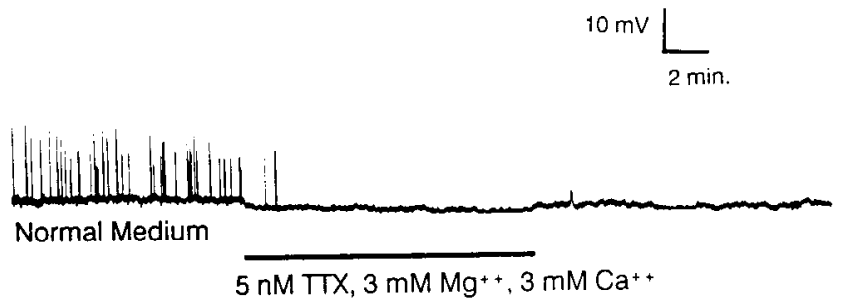

C

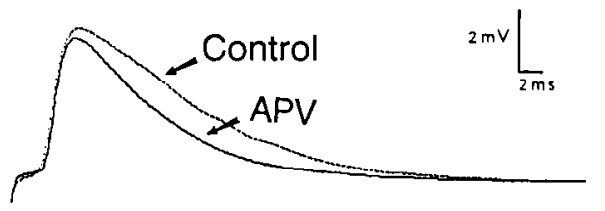

$0.8 \mathrm{mM} \mathrm{Mg}^{++}, 1.8 \mathrm{mM} \mathrm{Ca}^{++}$

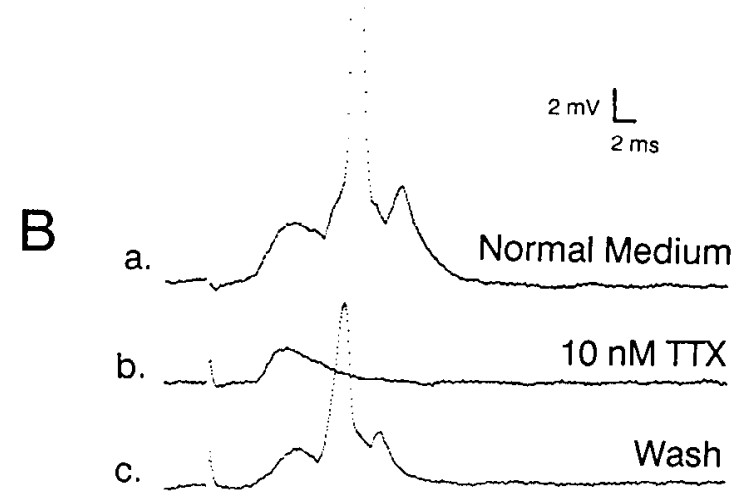

D

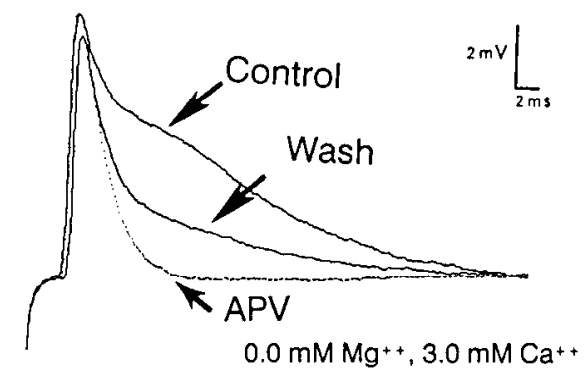

$E$

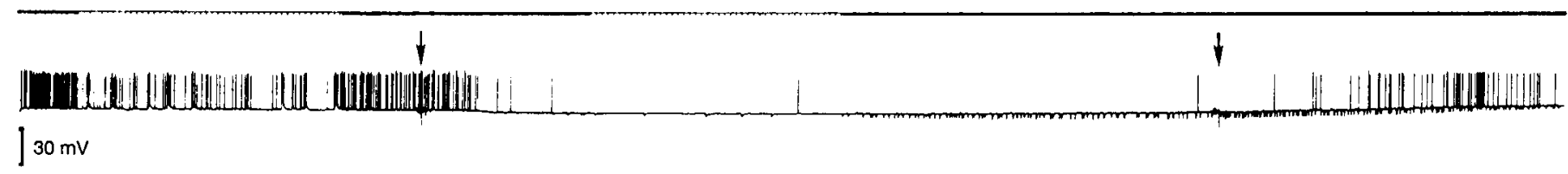

Figure 3. Effects of NMDA antagonism and dilute TTX on spontaneous activity and synaptic responses measured in VH neurons. $A$, Spontaneous activity ariscs from polysynaptic activity in the network of VH neurons in the central compartment, which is suppressed by perfusing dilute TTX (5-10 nM) and increasing the concentration of $\mathrm{Ca}^{2+}$ and $\mathrm{Mg}^{2+}$ to $3 \mathrm{mM}$ to reduce the excitability of neurons and diminish transmitter output. $B$, A paired intracellular recording between a DRG and a VH neuron shows that this treatment results in failure of polysynaptic responses in the VH neurons (cf. $a$ and $b$ ), but this concentration of TTX does not block action potentials to evoked stimulation, as is evident from the sustained monosynaptic response to evoked stimulation of DRG afferents (short-latency EPSP in $b$ ). $C$, The presence of NMDA channels in DRG-VH synapses and their sensitivity to APV antagonism is demonstrated by pressure ejection of $10 \mu \mathrm{M}$ APV from a pipette placed near a VH neuron in medium containing $2 \mathrm{mM} \mathrm{Ca}^{2+}$ and $0 \mathrm{mM} \mathrm{Mg}^{2+}$. The NMDA component of the EPSP elicited by intracellular stimulation of the presynaptic DRG neurons is demonstrated by the reduction in the slow component of the EPSP in the presence of APV. This effect of APV at doses up to $100 \mu \mathrm{M}$ is independent of calcium concentration, as is illustrated by the paired VH neuron recording in $3 \mathrm{mM} \mathrm{Ca}^{2+}(D)$. Inhibition of the NMDA component of the EPSP has been shown to be due to postsynaptic NMDA receptor blockade, and not to a presynaptic mechanism (unpublished observations). $E$, Spontaneous activity in the network of spinal cord neurons was reduced by $100 \mu \mathrm{M} \mathrm{APV}$, as is shown here in a recording made in a manner similar to that in $A$. This may be explained by loss of the long-latency NMDA component of the EPSP in APV, which reduces the EPSP amplitude resulting from temporal summation of multiple excitatory inputs. The inhibitory effect of APV subsided over several hours, but the frequency of bursting was significantly less after several days in APV. Time in seconds is indicated (upper trace in $E$ ).

ed to electrical stimulation. Stimulating DRG afferents, by extracellular current passed across the barrier, elicited monosynaptic EPSPs in the VH neurons, which often activated action potentials. Polysynaptic EPSPs and, more rarely, IPSPs were also elicited in response to stimulating DRG afferents, which activated VH neurons through intervening $\mathrm{VH}$ synapses. Administration of dilute TTX ( $5 \mathrm{nM}$ TTX in $3 \mathrm{~mm}$ calcium and 3 mM magnesium, or $10 \mathrm{nM}$ TTX in $1.8 \mathrm{~mm}$ calcium and $0.8 \mathrm{~mm}$ magnesium) suppressed the spontaneous and polysynaptic activity, thus reducing the network activity of VH neurons (Fig.
$3 A$ ). This inhibition did not prevent activation of EPSPs from DRG afferents that were stimulated electrically (Fig. $3 B$ ). However, this test does not completely exclude the possibility that monosynaptic activation during the chronic stimulation period might have been depressed in some inputs.

An NMDA component of the EPSP is revealed by the application of APV, which blocks the slow component of the EPSP (Fig. $3 C, D$ ). The inhibition of NMDA channel activation by APV was not affected by increasing the calcium concentration to $3 \mathrm{~mm}$ (Fig. 3D). As in other types of neurons (Forsythe and 
Table 1. Amplitude of EPSP ( $\mathrm{mV}$ ) for afferents converging onto the same spinal cord neuron in vitro

\begin{tabular}{|c|c|c|c|c|c|c|c|}
\hline \multirow[b]{3}{*}{ Medium $^{a}$} & \multicolumn{7}{|c|}{ Amplitude of EPSP (mV) } \\
\hline & \multicolumn{3}{|c|}{ Stimulated afferents } & \multicolumn{3}{|c|}{ Unstimulated afferents } & \multirow[b]{2}{*}{$p^{c}<$} \\
\hline & Mean & Median & $N^{b}$ & Mean & Median & $N^{b}$ & \\
\hline \multicolumn{8}{|l|}{ Postsynaptic activity } \\
\hline 1. TTX & 6.53 & 5.0 & 57 & 6.67 & 4.5 & 56 & NS (0.8) \\
\hline 2. $\mathrm{TTX}+\mathrm{APV}$ & 6.21 & 4.0 & 57 & 6.43 & 5.0 & 57 & NS (1) \\
\hline \multicolumn{8}{|l|}{ NMDA channel activation } \\
\hline 3. Normal* & 7.88 & 4.0 & 47 & 3.68 & 1.5 & 47 & 0.04 \\
\hline 4. Normal + APV* & 10.1 & 10.0 & 61 & 10.46 & 6.0 & 61 & NS (0.7) \\
\hline \multicolumn{8}{|c|}{ Increased extracellular calcium } \\
\hline 5. $3 / 3 / \mathrm{TTX}$ & 15.0 & 9.0 & 50 & 12.0 & 6.5 & 50 & 0.1 \\
\hline 6. $3 \mathrm{mM} \mathrm{Ca}^{2+}+\mathrm{APV}^{*}$ & 8.94 & 5.0 & 33 & 3.00 & 0.0 & 33 & 0.02 \\
\hline 7. $3 / 3 / \mathrm{TTX}+\mathrm{APV}$ & 10.3 & 8.0 & 35 & 5.90 & 3.0 & 35 & 0.05 \\
\hline
\end{tabular}

Synaptic strength following chronic stimulation of one set of convergent afferents is compared under different conditions of NMDA channel blockade with APV, increased calcium concentration, suppressed spontaneous activity in spinal cord network using dilute TTX, and reduced transmitter output with $3 \mathrm{~mm}$ magnesium.

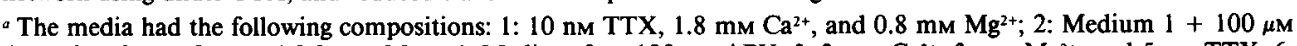

APV; 3: $1.8 \mathrm{mM} \mathrm{Ca}{ }^{2+}$ and $0.8 \mathrm{mM} \mathrm{Mg} \mathrm{Mg}^{2+}$ 4: Medium $3+100 \mu \mathrm{M} \mathrm{APV;} 5: 3 \mathrm{mM} \mathrm{Ca}^{2+}, 3 \mathrm{mM} \mathrm{Mg}^{2+}$, and $5 \mathrm{nM} \mathrm{TTX;} \mathrm{6:}$

$3 \mathrm{mM} \mathrm{Ca}^{2+}, 0.8 \mathrm{mM} \mathrm{Mg}{ }^{2+}$, and $100 \mu \mathrm{M}$ APV; 7: Medium 5 with $100 \mu \mathrm{M}$ APV.

$b$ Number of sides recorded.

c Mann-Whitney $U$ test, stimulated versus unstimulated; NS $=p>0.1$.

* These data have been reported previously (Nelson et al., 1990).

Westbrook, 1988), the fraction of the EPSP that was mediated by NMDA receptors varied widely among different cells. Despite the slow onset rate, the NMDA-mediated EPSP component does contribute to the peak amplitude of the EPSP to a variable extent (though not to the degree that its abolition would prevent significant postsynaptic depolarization). A pronounced transient suppression of network activity was detected following administration of $100 \mu \mathrm{M}$ APV to the central compartment (Fig. $3 E$ ). This inhibition was largely relieved within $1-2 \mathrm{hr}$, but the frequency and duration of spontaneous bursts of action potentials remained suppressed in chronically treated cultures compared to matched cultures not exposed to APV (Brenneman et al., 1990a,b).

\section{NMDA channel activation}

Plasticity induced by afferent stimulation (Nelson et al., 1989a) was replicated independently in these experiments (Table 1, medium 3). The afferents that had been stimulated for 3-5 d (Fig. $4 a^{\prime}$ ) were significantly stronger than the unstimulated convergent afferents (Fig. $4 a$; mean EPSP amplitudes, 7.9 vs. 3.7 $\mathrm{mV} ; p<0.04 ; n=47$ cells). There was also a greater number of inputs from the stimulated side ( 1.3 vs. 0.89 ; Table 2 ), but this difference was not statistically significant $(p<0.15)$. This also is consistent with previous results (Nelson et al., 1989a).

Inclusion of $100 \mu \mathrm{M} \mathrm{APV}$ in the medium during this stimulation period prevented the plasticity (Fig. $4, b^{\prime}$ vs. $b$ ). The mean EPSP amplitudes were 10.4 and $10.1 \mathrm{mV}$ from the unstimulated and stimulated convergents, respectively (NS; $n=61$ cells). There was no difference in the number of functional inputs from the stimulated and unstimulated sides (1.3 vs. 1.1; Table 2 ).

\section{Postsynaptic activity}

As illustrated in Figure $3 E$, APV treatment also suppressed network activity. A different method of suppressing network activity, which did not antagonize NMDA receptor activation, was used to test for effects on activity-dependent synaptic plas- ticity. After 3-5 d of afferent stimulation in the presence of 10 nM TTX, the amplitudes of the EPSPs from the stimulated (Fig. $\left.5 a^{\prime}\right)$ and unstimulated sides (Fig. $5 a$ ) were not significantly different (Table $1 ; 6.5$ vs. $6.7 \mathrm{mV} ; n=57$ cells). There was also no significant difference in the number of functional connections formed by active and inactive afferents on the spinal cord neuron following 3-5 d of stimulation in the presence of $10 \mathrm{nM}$ TTX ( 1.16 vs. $1.04 ; n=57$; Table 2 ). It is important to note that this concentration of TTX does not block sodium-dependent action potentials, but suppresses spontaneous activity in the network of spinal cord neurons by reducing neuronal excitability (Fig. $3 B$ ). This blockade of plasticity could be consistent with the intcrpretation that the network suppressing effect of APV is sufficient to explain the absence of plasticity when this antagonist is used, rather than being an effect due to a specific receptor.

Plasticity was also blocked if $10 \mathrm{nM}$ TTX and $100 \mu \mathrm{M}$ APV were administered in combination (Fig. $5, b^{\prime}$ vs. $b ; 6.2$ vs. 6.4 $\mathrm{mV}$ and 1.23 vs. 1.21 inputs per spinal cord neurons from stimulated and unstimulated afferents, respectively; $n=57$ cells).

\section{Increased extracellular calcium}

The blockade of plasticity in APV was prevented by increasing the concentration of calcium in the medium from a normal concentration of $1.8 \mathrm{~mm}$ to $3 \mathrm{~mm}$ during the stimulation period (Table 1, medium 6). The mean amplitude of the EPSPs from the stimulated afferents (Fig. $6 a^{\prime}$ ) was $8.9 \mathrm{mV}$ after chronic stimulation in the presence of $100 \mu \mathrm{M} A P V$ and $3 \mathrm{~mm}$ calcium, vs. $3.0 \mathrm{mV}$ for the unstimulated convergent afferents (Fig. $6 a$; $p<0.02 ; n=33$ ).

We were unable to detect any impairment in the ability of APV to antagonize the NMDA channel in $3 \mathrm{~mm}$ calcium; therefore, this result shows that activation of NMDA channels is not necessary for activity-dependent synaptic plasticity. Many extracellular and intracellular enzymatic reactions are affected by the concentration of calcium. Although this is a modest increase in external calcium concentration, it is of sufficient magnitude 

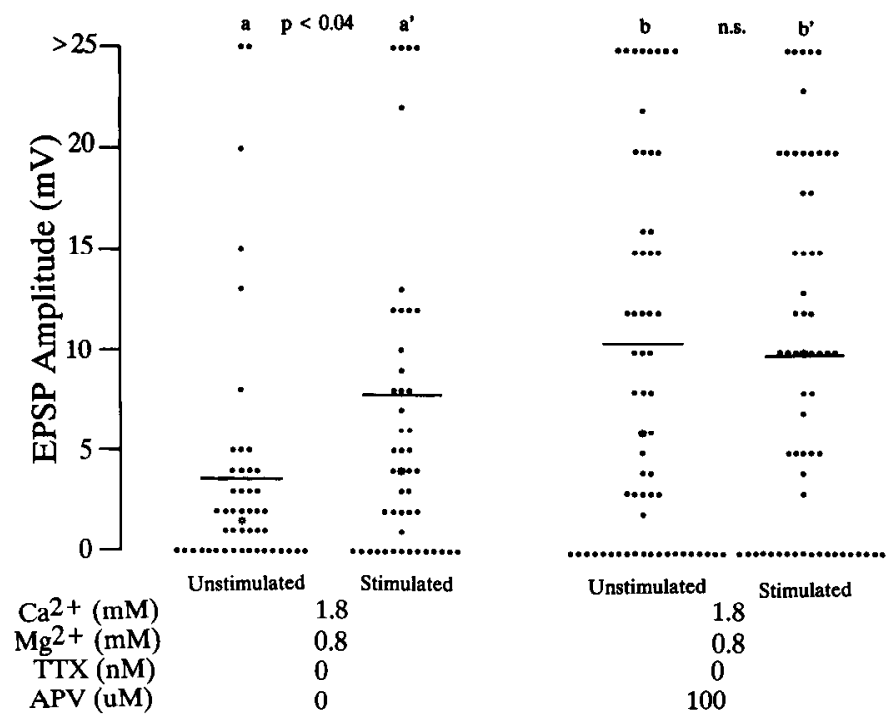

Figure 4. Effect of chronic electrical stimulation on strength of synapses from convergent afferents in normal medium and during NMDA receptor blockade. EPSPs were measured by intracellular recordings in VH neurons. The amplitude of EPSPs were compared between pairs of DRG afferents converging onto the same neuron, after stimulating one of the pairs of afferents in a phasic pattern for 3-5 d. The amplitude of the stimulated afferents $\left(a^{\prime}\right)$ was significantly greater than the unstimulated convergent afferents $(a)$. There was no significant difference in EPSP amplitudes for stimulated $\left(b^{\prime}\right)$ and unstimulated $(b)$ afferents if NMDA receptors were blocked with $100 \mu \mathrm{M}$ APV during the stimulation period. Mean amplitudes are indicated by a horizontal line, and the median of the distributions are indicated by an open asterisk (appearing solid when superimposed on a data point). Data have been rounded to integers and distributions have been truncated for display purposes. Statistical analysis was by the Mann-Whitney $U$ test because EPSP amplitudes are not normally distributed. to cause a marked increase in calcium influx and transmitter output (Nelson et al., 1983). Elevated external calcium concentration might influence plasticity via effects on presynaptic transmitter release (cf. Jia and Nelson, 1986), or through increased calcium influx into the postsynaptic neuron as a consequence of non-NMDA channel activation. In order to investigate whether the relief of the APV blockade of plasticity is dependent on increased transmitter output (and any additional effects on network activity), calcium was elevated to $3 \mathrm{~mm}$ in medium containing $100 \mu \mathrm{M}$ APV with $3 \mathrm{mM}$ magnesium to reduce transmitter output and 5 nM TTX to reduce network activity. Under these conditions, activity-dependent plasticity was restored despite the blockade of NMDA channel activation (Table 1). The amplitudes of the EPSPs from the stimulated (Fig. $6 b^{\prime}$ ) and unstimulated convergent afferents (Fig. 6b) were significantly different ( 10.3 vs. $5.9 \mathrm{mV} ; p<0.05 ; n=35$ cells). Plasticity was also suggested in terms of the number of functional inputs under conditions where calcium was elevated to $3 \mathrm{~mm}$ in the presence of $100 \mu \mathrm{M}$ APV (Table $2, p<0.08$ and 0.008 ). Other unknown presynaptic effects of increased calcium are not ruled out by these experiments. Stimulus-associated changes in calcium influx into growth cones were investigated in this preparation, but the cffccts on growth conc motility do not explain the activity-dependent changes in synaptic strength and number (Fields et al., 1990a).

Elevated calcium also appears to have relieved the blockade of plasticity caused by suppressing network activity with dilute TTX, but this effect is uncertain. Stimulation in the presence of $3 \mathrm{mM} \mathrm{Ca}^{2+}, 3 \mathrm{mM} \mathrm{Mg}{ }^{2+}, 5 \mathrm{nM}$ TTX, and no APV resulted in more inputs from the active side (1.67 vs. $1.31 ; p<0.05 ; n$ $=61$ cells), and the amplitudes of the EPSPs were larger from the stimulated side (Fig. $6, c^{\prime}$ vs. $c$; 15 vs. $12 \mathrm{mV} ; p<0.099$; $n=50$ cells), but the difference in amplitudes failed to reach the 0.05 probability level with a Mann-Whitney $U$ test. Al-

Table 2. Number of functional inputs to spinal cord neurons from each side compartment after chronic stimulation of afferents on one side

\begin{tabular}{|c|c|c|c|c|c|c|c|c|c|c|c|c|c|c|c|}
\hline \multirow[b]{3}{*}{ Medium $^{a}$} & \multicolumn{7}{|c|}{ Stimulated side } & \multicolumn{7}{|c|}{ Unstimulated side } & \multirow[b]{3}{*}{$p^{c}<$} \\
\hline & \multicolumn{5}{|c|}{ Number of DRG inputs } & \multirow[b]{2}{*}{$N^{b}$} & \multirow[b]{2}{*}{ Mean } & \multicolumn{5}{|c|}{ Number of DRG inputs } & \multirow[b]{2}{*}{$N^{b}$} & \multirow[b]{2}{*}{ Mean } & \\
\hline & 0 & 1 & 2 & 3 & $>3$ & & & 0 & 1 & 2 & 3 & $>3$ & & & \\
\hline \multicolumn{16}{|l|}{ Postsynaptic activity } \\
\hline 1. TTX & $19^{c}$ & 56 & 14 & 10 & 0 & 57 & 1.16 & 27 & 50 & 16 & 7 & 0 & 56 & 1.04 & NS (0.5) \\
\hline 2. TTX + APV & 23 & 46 & 19 & 10 & 2 & 57 & 1.23 & 30 & 32 & 26 & 12 & 0 & 57 & 0.862 & NS (1) \\
\hline \multicolumn{16}{|l|}{ NMDA channel activation } \\
\hline 3. Normal* & 30 & 30 & 24 & 9 & 6 & 46 & 1.30 & 35 & 44 & 20 & 2 & 0 & 46 & 0.891 & 0.1 \\
\hline 4. Normal + APV* & 29 & 29 & 26 & 15 & 0 & 61 & 1.26 & 34 & 28 & 29 & 6 & 2 & 61 & 1.13 & NS $(0.5)$ \\
\hline \multicolumn{16}{|c|}{ Increased extracellular calcium } \\
\hline 5. $3 / 3 / \mathrm{TTX}$ & 13 & 36 & 29 & 16 & 5 & 61 & 1.67 & 21 & 47 & 18 & 7 & 7 & 61 & 1.31 & 0.05 \\
\hline 6. $3 \mathrm{mM} \mathrm{Ca}^{2+}+\mathrm{APV}^{*}$ & 27 & 36 & 27 & 9 & 0 & 33 & 1.18 & 54 & 36 & 9 & 0 & 0 & 33 & 0.545 & 0.008 \\
\hline 7. $3 / 3 / \mathrm{TTX}+\mathrm{APV}$ & 19 & 45 & 19 & 19 & 2 & 42 & 1.36 & 33 & 43 & 21 & 2 & 0 & 42 & 0.929 & 0.08 \\
\hline
\end{tabular}

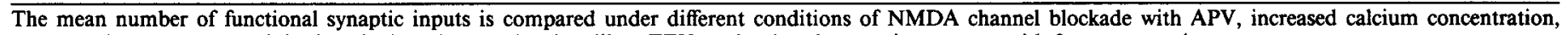
suppressed spontaneous activity in spinal cord network using dilute TTX, and reduced transmitter output with 3 mM magnesium.

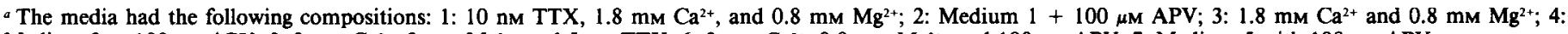

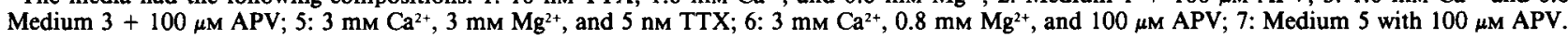

${ }^{b}$ Number of sides recorded.

' Mann-Whitney $U$ test, stimulated versus unstimulated; NS $=p>0.1$.

${ }^{d}$ Frequency (\% occurrence).

* These data have been reported previously (Nelson et al., 1990). 
though this suggests a trend toward plasticity under conditions of reduced network activity and elevated calcium, the lack of statistical significance would render equivocal any interpretation for or against plasticity in this case.

In general, the changes in synaptic strength parallel the changes in number of functional inputs; however, the amplitude differences are not caused entirely by differences in connectivity. This is shown by comparing the amplitude of the lowest threshold unitary inputs to each spinal cord neuron. The amplitude of the unitary inputs was significantly different between the stimulated and unstimulated afferents (e.g., 5.6 vs. $2.1 \mathrm{mV} ; p<0.01 ; n=$ 33 neurons in $3 \mathrm{~mm} \mathrm{Ca}^{2+}, 3 \mathrm{~mm} \mathrm{Mg}^{2+}, 5 \mathrm{nM}$ TTX, and $100 \mu \mathrm{M}$ APV).

Although elevated calcium in the presynaptic terminal may have important effects, and the results of these experiments must be tested in vivo, a summary of the conditions tested in this preparation and organized according to whether or not afferent stimulation induced synaptic plasticity reveals that the only variable consistently associated with plasticity is adequate calcium for influx into the postsynaptic neuron (Fig. 7, Table 3).

\section{Discussion}

The strength, and under some conditions the number, of synapses was increased from afferents that were stimulated compared to convergent afferents that were not stimulated. This activity-dependent plasticity was blocked by APV, which indicates that activation of NMDA receptors interacts with the mechanism leading to the difference in synaptic strength and number of synapses in stimulated and nonstimulated afferents. However, when calcium was elevated and network activity was suppressed (using $5 \mathrm{nM}$ TTX, $3 \mathrm{~mm}$ calcium, and $3 \mathrm{~mm}$ magnesium), blocking NMDA receptor activation no longer inhibited the activity-related difference in synaptic strength or number of functionally connected axons. Collectively, the results show that 2 conditions support activity-dependent synaptic plasticity: (1) sufficient postsynaptic activity with NMDA activation, or (2) elevated calcium concentration (Table 3). NMDA activation is neither necessary nor sufficient.

There is good reason to believe that the first condition may be a physiological means of bringing about the situation provided under the second condition, namely, providing adequate influx of calcium into the postsynaptic neuron in an activitydependent manner. Activation of NMDA channels is believed to produce persistent changes in synaptic efficacy through cell

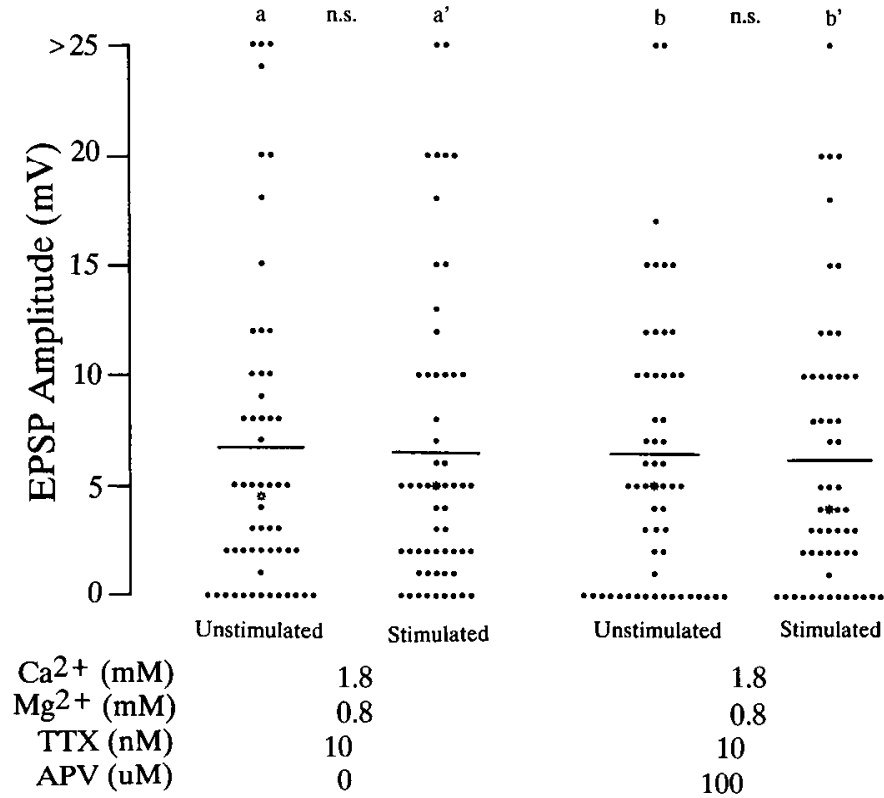

Figure 5. Suppressing polysynaptic activity abolished plasticity induced by afferent stimulation. There was no significant difference in amplitude of EPSPs from stimulated $\left(a^{\prime}\right)$ or unstimulated $(a)$ convergent afferents when spontaneous activity was suppressed by 10 nм TTX. This concentration of TTX increases the failure of polysynaptic connections, thus decreasing spontaneous activity, but it leaves the monosynaptic connection responsive to afferent stimulation (cf. Fig. $3 B$ ). Plasticity was also blocked under these conditions in the presence of $100 \mu \mathrm{M}$ APV $\left(b\right.$ vs. $\left.b^{\prime}\right)$. These results suggest that the molecular mechanism for the activity-dependent synaptic plasticity observed in normal medium (Fig. 4) depends on sufficient postsynaptic activity. Symbols are as described in Figure 4.

biological mechanisms dependent on influx of calcium through the activated channels (MacDermott et al., 1986; Bear et al., 1987; Mayer and Westbrook, 1987; Mayer et al., 1987; Ascher and Nowak, 1988). Calcium also passes into the cell in an activity-dependent manner via voltage-sensitive calcium channels (Hagiwara and Byerley, 1981; Stanfield, 1986; Miller, 1987; Llinas, 1988). A cell biological mechanism operating as a function of calcium influx need not require receptor specificity. The concentration of $\left[\mathrm{Ca}^{2+}\right]_{i}$ is a function of the dynamic balance between influx, efflux, sequestration, and release from internal stores. All of these are sensitive to electrical activation and are

Table 3. Association between activity-dependent plasticity and the predicted effects of different media on [Ca $\left.{ }^{2+}\right]_{i}$

$\begin{array}{lll}\text { Medium } & \text { Increased plasticity } & \text { Decreased plasticity }\end{array}$

\begin{tabular}{|c|c|c|c|c|c|c|}
\hline $\mathbf{M}$ & $1.8 \mathrm{mM} \mathrm{Ca}^{2+}$ & $3 \mathrm{mM} \mathrm{Ca}^{2+}$ & $3 \mathrm{mM} \mathrm{Ca}^{2+}$ & & & \\
\hline $\mathrm{e}$ & & $3 \mathrm{mM} \mathrm{Mg}^{2+}$ & & & & \\
\hline d & & 5 nм TTX & & & 10 nм TTX & 10 nм TTX \\
\hline 1 & & $0.1 \mathrm{mM} \mathrm{APV}$ & $0.1 \mathrm{mM} \mathrm{APV}$ & $0.1 \mathrm{~mm}$ APV & & $0.1 \mathrm{mM} \mathrm{APV}$ \\
\hline \multicolumn{7}{|l|}{$\mathbf{a}^{a}$} \\
\hline \multicolumn{7}{|l|}{ Factor } \\
\hline Network activity & + & 0 & $(+)$ & $(+)$ & 0 & 0 \\
\hline NMDA activation & + & 0 & 0 & 0 & + & 0 \\
\hline High calcium & 0 & + & + & 0 & 0 & 0 \\
\hline
\end{tabular}

+ , tendency to increase $\left[\mathrm{Ca}^{2+}\right]_{;} ; 0$, lack of tendency to increase $\left[\mathrm{Ca}^{2+}\right]_{i} ;(+)$, reduced tendency to increase $\left[\mathrm{Ca}^{2+}\right]_{i}$.

a Normal medium contains $1.8 \mathrm{~mm} \mathrm{Ca}{ }^{2+}, 0.8 \mathrm{~mm} \mathrm{Mg}^{2+}$, no TTX, and no APV. 


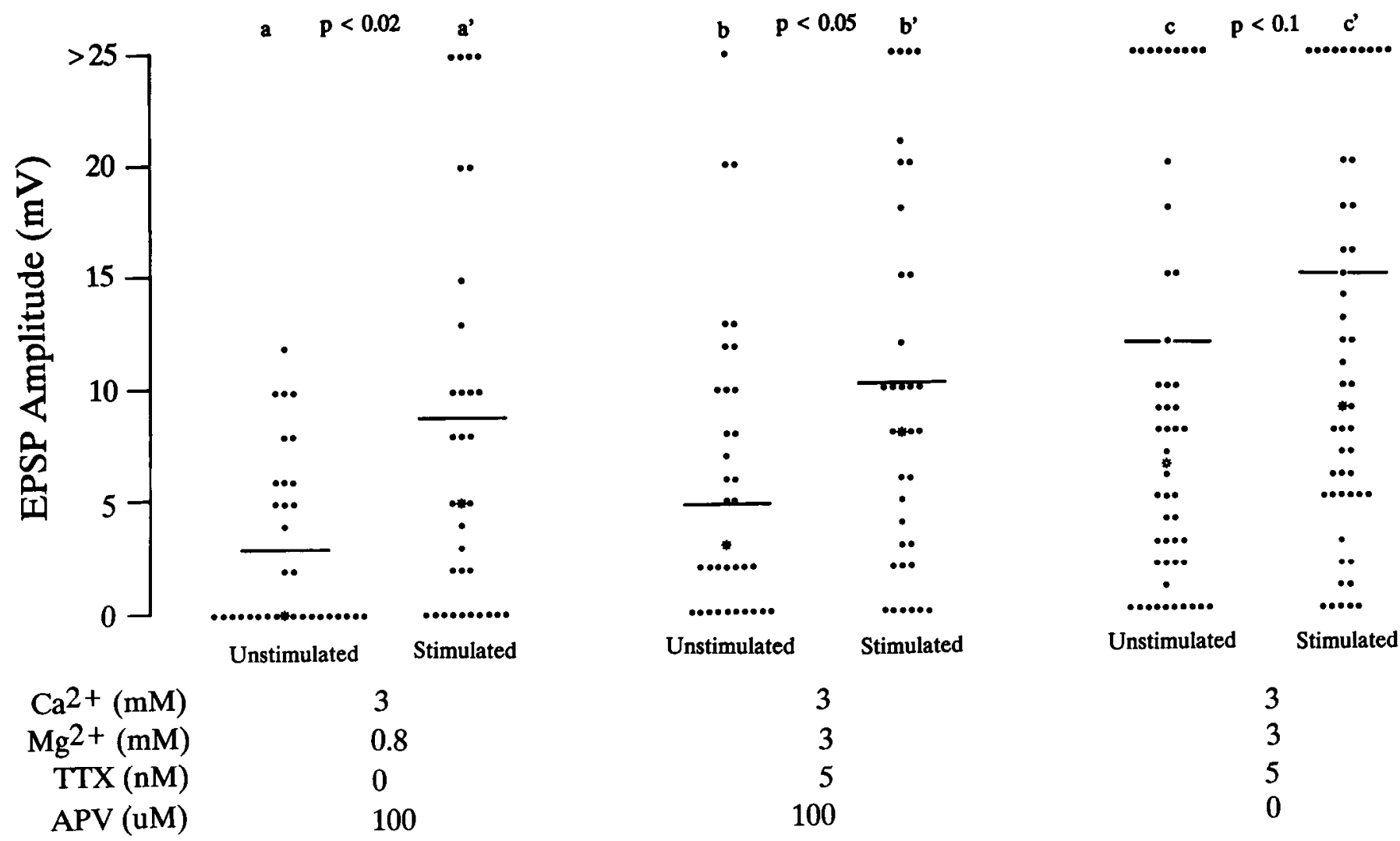

Figure 6. Activity-dependent plasticity occurred during NMDA channel blockade when concentration of calcium was increased from normal value of $1.8 \mathrm{~mm}$ to $3 \mathrm{mM}$. The EPSP amplitudes elicited by stimulated afferents $\left(a^{\prime}\right)$ were significantly greater than unstimulated convergent afferents (a) in the presence of $100 \mu \mathrm{M}$ APV and $3 \mathrm{~mm}$ calcium. This calcium-dependent effect was also observed when transmitter output was reduced by elevating the concentration of magnesium to $3 \mathrm{mM}$ and suppressing network activity with $5 \mathrm{nM}$ TTX $\left(b\right.$ vs. $\left.b^{\prime}\right)$. Elevating the calcium concentration also tended to restore the activity-dependent plasticity that is blocked by suppressing polysynaptic activity, though this effect was not significantly different at the 0.05 level $\left(c\right.$ vs. $\left.c^{\prime}\right)$. These results suggest that the mechanism for activity-dependent plasticity can operate via calcium-dependent processes that are not dependent on NMDA receptor activation. Symbols are as described in Figure 4.

independently regulated by various physiological mechanisms. In a calcium-mediated mechanism of plasticity, the postsynaptic neuron would not only be responsive to activity of a specific receptor subtype to control changes in efficacy, but also to a considerably wider scope of activity-dependent phenomena, including the general level of activity in the postsynaptic network and the activity-dependent history of physiological mechanisms maintaining calcium homeostasis (e.g., Fields et al., 1990a,b). The blockade of plasticity in dilute TTX is support for this interpretation (Table 3). Furthermore, this result would invalidate an interpretation of the Hebbian model stated strictly in terms of NMDA activation, because NMDA channels were not blocked by the dilute TTX used to suppress network activity. In Hebbian terms, the "adequate level of postsynaptic response" must include some variable significantly impacted by the level of network activity. Activity-dependent calcium influx through both NMDA and non-NMDA channels may represent such a response.

Superficially similar phenomena of activity-dependent plasticity in different types of neurons appear to operate through different mechanisms. Even within the hippocampus, NMDAdependent and NMDA-independent forms of LTP have been described (reviews by Brown et al., 1989; Nicoll et al., 1988). Both forms of plasticity are sensitive to changes in $\left[\mathrm{Ca}^{2+}\right]_{i}$, however (Wickens, 1988; Jaffee and Johnston, 1989; Williams and
Johnston, 1989). Moreover in hippocampal regions where evidence suggests NMDA is involved in the mechanism of LTP, long-lasting potentiation can be initiated without NMDA activation, either by intracellular release of $\mathrm{Ca}^{2+}$ (Malenka et al., 1988), or by incubation of the hippocampal slice in elevated calcium concentration (Turner et al., 1982; Bliss et al., 1984; Mody et al., 1984; Feasy et al., 1985; Reymann et al., 1986). Blocking voltage-sensitive calcium channels (Izumi et al., 1987) or reducing the concentration of extracellular calcium to bclow $2 \mathrm{~mm}$ (Dunwiddie and Lynch 1979; Wigstrom et al., 1979) impairs the ability to initiate LTP in hippocampal slice preparations.

The extent to which the plastic phenomenon in our in vitro preparation is related to the mechanism of LTP is uncertain. The 2 phenomena have very different time courses of initiation (hours as compared to days). In addition to persistent changes in gain for existing synapses, long-term developmental changes modeled in this in vitro preparation are presumed to involve synaptogenesis and synapse elimination. The data in their present form do not permit us to differentiate between these 2 antagonistic processes that determine the number of functional DRG inputs to VH neurons. These questions could be investigated in this preparations by serial electrophysiological recording and morphological techniques. The data concerning the number of functional inputs (Table 2) show that the restored 


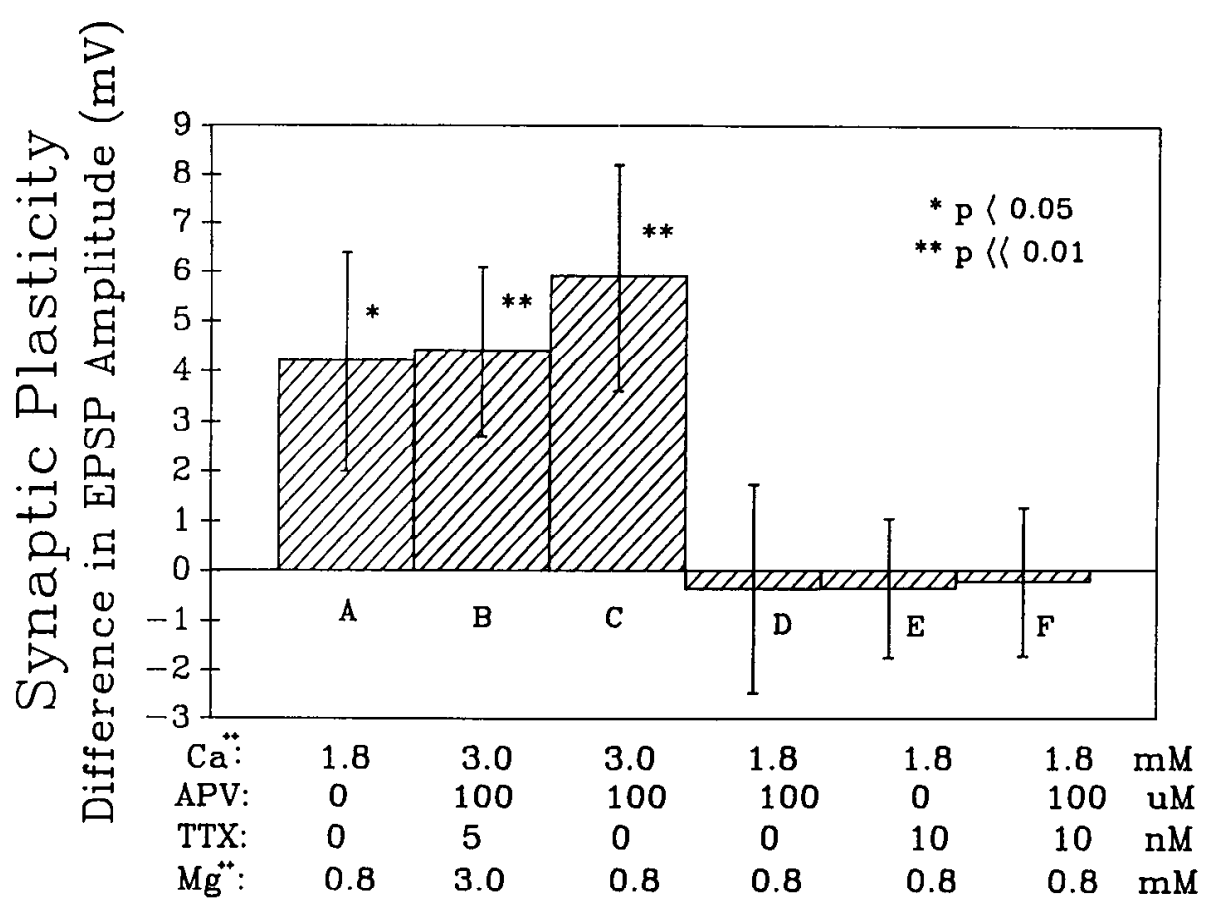

Figure 7. Summary of effects of postsynaptic activity, NMDA channel activation, and calcium concentration on synaptic plasticity. Values represent the mean of differences in EPSP amplitude between the stimulated and unstimulated afferents to each spinal cord neuron (stimulated minus unstimulated). Activity-dependent synaptic plasticity is defined here as a mean difference between convergent afferents to the same postsynaptic neuron, which is significantly greater than $0 \mathrm{mV}(t$ test). When the calcium concentration is $1.8 \mathrm{~mm}$, plasticity is not observed if NMDA channel activation is blocked with APV $(D, E)$, or network activity is suppressed with dilute TTX $(E, F)$. Plasticity is observed in media with 3 mM calcium, despite APV blockade of NMDA channel activation $(C)$ or NMDA channel blockade with TTX and $3 \mathrm{mM} \mathrm{Mg}^{2+} \mathrm{F}$ to reduce transmitter output $(B)$. Network activity, NMDA channel activation, and increased extracellular calcium all affect the magnitude of calcium influx into the postsynaptic neuron. Tabulating these results according to the presumed effects of the different media on $\left[\mathrm{Ca}^{2+}\right]_{i}$ (Table 3 ) supports the argument that plasticity is dependent on sufficient postsynaptic activation to bring about a critical level of calcium influx. Error bars represent \pm SEM.

plasticity in elevated calcium under conditions of NMDA channel blockade is due to the small number of unstimulated convergent inputs. Additional experiments will be necessary to test whether this effect is due to a calcium-dependent process that increases elimination in a competitive manner, rather than a calcium-induced inhibition of processes that increase synaptic stabilization or synaptogenesis. This difficult distinction is not peculiar to this in vitro preparation, but is an important consideration in any study of synaptic restructuring during development.

It is possible that factors increasing the strength or number of synaptic connections are dependent on NMDA receptor activation, but processes decreasing synaptic efficacy or promoting synapse elimination are controlled by second-messenger cascades that are linked to non-NMDA receptors (Nicoletti et al., 1986; Sugiyama et al., 1987), or that have no receptor specificity but are calcium dependent (e.g., calcium-dependent protease; O'Brien et al., 1984; Connold et al., 1986; Simon et al., 1987; Swanson and Vrbová, 1987). Evidence is beginning to emerge from studies of the visual system (Dudek and Bear, 1989) and hippocampus (Chattarji et al., 1989) that NMDA activation may not be involved in the processes that decrease synaptic efficacy.

A comparison of EPSP amplitude across different media in Experiment 1 provides some insight into the reasons for the pharmacological blockade of plasticity, which must be tested directly in other experiments. Consistent with previous results, a 3-way ANOVA of these data (Tables 4,5) shows that a primary factor affecting the strength of EPSPs is afferent stimulation, which caused a significant increase in EPSP amplitude $(p<$
0.02 ; mean $=11.3$ and $8.3 \mathrm{mV}$ for the stimulated and unstimulated afferents, respectively, collapsed across all other factors). In addition, EPSP amplitude was increased significantly by the $3 \mathrm{mM} \mathrm{Ca}^{2+}, 3 \mathrm{mM} \mathrm{Mg}^{2+}, 5 \mathrm{nM}$ TTX medium $(p<0.023)$, but the effect of this medium depended on whether or not APV was included. This is shown by the highly significant antagonistic interaction between APV and treatment with the medium containing $3 \mathrm{mM} \mathrm{Ca}^{2+}, 3 \mathrm{mM} \mathrm{Mg}^{2+}$, and $5 \mathrm{nM}$ TTX $(p<0.0001)$. In normal medium, APV caused a significant increase in EPSP amplitudes ( $p<0.0018 ; 2$-way ANOVA), but in medium containing $3 \mathrm{~mm} \mathrm{Ca}^{2+}, 3 \mathrm{~mm} \mathrm{Mg}^{2+}$, and 5 nм TTX, APV caused a significant decrease in EPSP amplitude $(p<0.009 ; 2$-way ANOVA). This antagonistic interaction between the effects of APV and the medium containing elevated $\mathrm{Ca}^{2+}$ is consistent with the possibility that the positive effects of APV are related to changes in $\left[\mathrm{Ca}^{2+}\right]_{i}$. The blockade by APV of stimulus-induced increase in EPSP amplitude may also operate through changes in calcium, because APV was not effective in blocking activity-dependent plasticity if the calcium concentration was increased to $3 \mathrm{~mm}$. Several inferences can be drawn from this analysis: (1) Synaptic strength may be increased by stimulation when NMDA channels are blocked (10.1 vs. $7.88 \mathrm{mV}$; stimulated afferents in APV and normal medium, respectively; $p=0.1$; Mann-Whitney $U$ ), but the selective decrease in synaptic strength of unstimulated afferents is abolished in APV ( 10.1 vs. $10.4 \mathrm{mV}$, stimulated vs. unstimulated afferents, respectively, in APV). (2) Elevating external calcium to $3 \mathrm{mM}$ (also containing $3 \mathrm{mM} \mathrm{Mg}^{2+}$ and 5 nM TTX) increases EPSP amplitude without regard to afferent stimulation (stimulated afferents increased from $7.88 \mathrm{mV}$ in 


\begin{tabular}{|c|c|c|c|}
\hline Factor $^{a}$ & df & SS & $p<$ \\
\hline \multicolumn{4}{|c|}{ Three-factor ANOVA on EPSP amplitude (mV) } \\
\hline Between subjects & 386 & $56,655.77$ & \\
\hline Stimulation & 1 & 752.95 & $0.020^{*}$ \\
\hline 3/3/TTX & 1 & 716.76 & $0.023^{*}$ \\
\hline APV & 1 & 17.95 & NS $(0.72)$ \\
\hline \multicolumn{4}{|l|}{ Second-order interactions } \\
\hline $3 / 3 / \mathrm{TTX}+$ stimulation & 1 & 67.13 & NS (0.49) \\
\hline $3 / 3 / \mathrm{TTX}+\mathrm{APV}$ & 1 & 2320.18 & $0.0001^{* * *}$ \\
\hline Stimulation + APV & 1 & 57.53 & NS $(0.52)$ \\
\hline \multicolumn{4}{|l|}{ Third-order interactions } \\
\hline 3/3/TTX + stimulation + APV & 1 & 201.38 & NS $(0.23)$ \\
\hline Subjects within groups & 379 & $52,478.86$ & \\
\hline \multicolumn{4}{|c|}{ Two-factor ANOVA on EPSP amplitudes $(\mathrm{mV})$ in normal medium } \\
\hline Between subjects & 216 & $25,147.48$ & \\
\hline Stimulation & 1 & 212.72 & NS $(0.17)$ \\
\hline APV & 1 & 1108.28 & $0.0018^{* * *}$ \\
\hline Stimulation + APV & 1 & 272.31 & NS $(0.12)$ \\
\hline Subjects within groups & 213 & $23,596.41$ & \\
\hline \multicolumn{4}{|c|}{ Two-factor ANOVA on EPSP amplitudes (mV) in medium with } \\
\hline \multicolumn{4}{|l|}{$3 \mathrm{mM} \mathrm{Ca}^{2+}, 3 \mathrm{mM} \mathrm{Mg}{ }^{2+}$, and $5 \mathrm{nM}$ TTX } \\
\hline Between subjects & 169 & $30,660.64$ & \\
\hline Stimulation & 1 & 562.18 & 0.074 \\
\hline APV & 1 & 1215.93 & $0.0090^{* *}$ \\
\hline Stimulation + APV & 1 & 19.32 & NS $(0.74)$ \\
\hline Subjects within groups & 166 & $28,882.47$ & \\
\hline
\end{tabular}

normal medium to $15 \mathrm{mV}$ in the $3 \mathrm{mM} \mathrm{Ca}{ }^{2+}, 3 \mathrm{mM} \mathrm{Mg}^{2+}, 5 \mathrm{nM}$ TTX medium; $p<0.002$; Mann-Whitney $U$; unstimulated afferents increased, respectively, from 3.68 to $12 \mathrm{mV} ; p<0.0002$ ), but there is still evidence for activity-dependent competition, because unstimulated afferents exhibit less increase in amplitude than stimulated afferents (12 vs. $15 \mathrm{mV} ; p<0.1$; Mann-Whitney $U$ ). (3) The effects of APV in increasing the EPSP amplitude nonselectively and in antagonizing activity-dependent synaptic increase in synaptic strength are mediated through a mechanism interacting with $\left[\mathrm{Ca}^{2+}\right]_{i}$ via calcium influx through channels other than the NMDA channel. This analysis provides useful hypotheses for further study, which could evaluate other phenomena that might be affected by these treatments, including any

\begin{tabular}{|c|c|c|c|}
\hline Factor $^{a}$ & df & $x^{2}$ & $p<$ \\
\hline \multicolumn{4}{|l|}{ Between subjects } \\
\hline Stimulation & 1 & 4.289 & $0.04^{*}$ \\
\hline 3/3/TTX & 1 & 0.915 & NS $(0.3)$ \\
\hline APV & 1 & 1.602 & NS (0.2) \\
\hline \multicolumn{4}{|l|}{ Second-order interactions } \\
\hline 3/3/TTX + stimulation & 1 & 0.133 & NS $(0.7)$ \\
\hline $3 / 3 / \mathrm{TTX}+\mathrm{APV}$ & 1 & 4.027 & $0.04^{*}$ \\
\hline Stimulation + APV & 1 & 0.133 & NS $(0.7)$ \\
\hline
\end{tabular}

presynaptic effects, or processes that may be unique to tissue culture.

This set of results do not fit the dual receptor hypothesis (NMDA activation involved in increased synaptic strength and non-NMDA activation involved in decreased synaptic strength; cf. Bear and Cooper, 1990; Nelson et al., 1990) as well as would be expected from first principles. An interpretation worthy of further consideration is one where activity-dependent synaptic plasticity results from 2 antagonistic processes: one increasing synaptic strength and another decreasing synaptic strength, but both acting through changes in intracellular calcium (Nelson et al., 1990). Such a mechanism would also incorporate and be compatible with the effects of reduced spontaneous network activity on synaptic strength, assuming postsynaptic activity increases $\left[\mathrm{Ca}^{2+}\right]_{i}$ or regulates calcium buffering capacity. Future studies directed at elucidating the activity-dependent changes in $\left[\mathrm{Ca}^{2+}\right]_{i}$ and calcium homeostatic mechanisms, and the relative sensitivity to calcium of processes increasing synaptic efficacy versus decreasing synaptic efficacy, are feasible and would be helpful in improving our understanding of how activity modifies development of the nervous system according to sensory or functional experience.

\section{References}

Archer SM, Dubin MW, Stark LS (1982) Abnormal development of kitten retino-geniculate connectivity in the absence of action potentials. Science 217:743-745

Artola W, Singer W (1987) Long-term potentiation and NMDA receptors in rat visual cortex. Nature 330:649-652. 
Ascher P, Nowak $\mathrm{L}$ (1988) The role of divalent cations in the $\mathrm{N}$-methyl-D-aspartate responses of mouse central neurones in culture. J Physiol (Lond) 399:247-266.

Baimbridge KG, Miller JJ (1981) Calcium uptake and retention during long-term potentiation of neuronal activity in the rat hippocampal slice preparation. Brain Res 221:299-305.

Bear MF, Cooper LN (1990) Molecular mechanisms for synaptic modification in the visual cortex: interaction between theory and experiment. In: Neuroscience and connectionist theory (Gluck MA, Rumelhart DE, eds), pp 65-93. New Jersey: Lawrence Erlbaum.

Bcar MF, Cooper LN, Ebncr FF (1987) A physiological basis for a theory of synapse modification. Science $23: 42-47$.

Berry MS, Penreath VW (1976) Criteria for distinguishing between monosynaptic and polysynaptic transmission. Brain Res 105:1-20.

Bliss TVP, Dolphin AC, Feasy KJ (1984) Elevated calcium induces a long-lasting potentiation of commisural responses in hippocampal CA3 cells of the rat in vivo. J Physiol (Lond) 350:65P.

Brenneman DE, Yu C, Nelson PG (1990a) Multi-determinate regulation of neuronal survival: neuropeptides, excitatory amino acids and bioelectric activity. Int J Dev Neurosci 8:371-378.

Brenneman DE, Forsythe ID, Nicol T, Nelson PG (1990b) $N$-methylD-aspartate receptors influence neuronal survival in developing spinal cord cultures. Dev Brain Res 51:63-68.

Brown TH, Ganong AH, Kairiss EW, Keenan CL, Kelso SR (1989) Long-term potentiation in two synaptic systems of the hippocampal brain slice. In: Neural models of plasticity (Byrne JH, Berry WO, eds), pp 266-306. New York: Academic.

Callaway EM, Soha JM, Van Essen DC (1989) Differential loss of neuromuscular connections according to activity level and spinal position of neonatal rabbit soleus motor neurons. J Neurosci 9:18061824

Campenot R (1977) Local control of neurite development by nerve growth factor. Proc Natl Acad Sci USA 74:4516-4519.

Chattarji S, Stanton PK, Sejnowski TJ (1989) Induction of associative long-term depression (LTD) in hippocampal field CA3 is not mediated by NMDA receptors. Soc Neurosci Abstr 15:165.

Cline HT, Constantine-Paton M (1989) NMDA reaceptor antagonists disrupt the retinotectal topographic map. Neuron 3:413-426.

Clinc HT, Debski EA, Constantinc-Paton M (1987) $\mathrm{N}$-methyl-D-aspartate receptor antagonist desegregates eye-specific stripes. Proc Natl Acad Sci USA 84:4342-4345.

Collingridge GL, Bliss TVP (1987) NMDA receptors-their role in long-term potentiation. Trends Neurosci 10:288-293.

Collingridge GL, Lester RAJ (1989) Excitatory amino acid receptors in the vertebrate central nervous system. Pharmacol Rev 40:145-210.

Collingridge GL, Kehl SJ, McLennan H (1983) Excitatory amino acids in synaptic transmission of the Schaffer commissural pathway of the rat hippocampus. J Physiol (Lond) 334:33-46.

Connold AL, Evers JV, Vrbová G (1986) Effect of low calcium and protease inhibitors on synapse elimination during postnatal development in the rat soleus muscle. Dev Brain Res 28:99-107.

Debski EA, Cline HT, Constantine-Paton M (1990) Activity-dependent tuning and the NMDA receptor. J Ncurobiol 21:18-32.

Dubin MW, Stark LA, Archer SM (1986) A role for action-potential activity in the development of neuronal connections in the kitten retinogeniculate pathway. J Neurosci 6:1021-1036.

Dudek SM, Bear MF (1989) A biochemical correlate of the critical period for synaptic modification in the visual cortex. Science 246: 673-675.

Dunwiddie TV, Lynch G (1979) The relationship between extracellular calcium concentration and the induction of hippocampal longterm potentiation: evidence for a postsynaptic locus of control. Brain Res 169:103-110.

Eccles JC (1983) Calcium in long-term potentiation as a model for memory. Neuroscience 10:1071-1081.

Fawcett JW, O'Leary DM (1985) The role of electrical activity in the formation of topographical maps in the nervous system. Trends Neurosci 8:201-206.

Feasy KJ, Lynch MA, Bliss TVP (1985) $\mathrm{Ca}^{++}$-long-term potentiation in $\mathrm{CA} 3$ region of the hippocampus is associated with increased release of aspartate: an in vivo study in the rat. Neurosci Lett [Suppl] 21:45.

Fields RD, Yu C, Nelson PG (1989) Network activity, afferent activity, and the role of NMDA channels in synaptic plasticity in vitro. Soc Neurosci Abstr 15:126.

Fields RD, Neale EA, Nelson PG (1990a) Effects of patterned electrical activity on neurite outgrowth from mouse sensory neurons. J Neurosci 10:2950-2964.

Fields RD, Guthrie PB, Nelson PG, Kater SB (1990b) Calcium homeostatic capacity is regulated by patterned electrical activity in growth cones of mouse DRG neurons. Soc Neurosci Abstr 16:457.

Forsythe ID, Westbrook GL (1988) Slow excitatory postsynaptic currents mediated by $N$-methyl-D-aspartate receptors on cultured mouse central neurones. J Physiol (Lond) 396:515-533.

Fox K, Armstrong-James M (1986) The role of the anterior intralaminar nuclei and NMDA receptors in the generation of spontaneous bursts in rat neocortical neurones. Exp Brain Res 63:505-518.

Fox K, Sato H, Daw N (1989) The location and function of NMDA receptors in cat and kitten visual cortex. J Neurosci 9:2443-2454.

Gu Q, Bear M, Singer W (1989) Blockade of NMDA-receptor prevents ocularity changes in kitten visual cortex after reversed monocular deprivation. Dev Brain Res 47:281-288.

Hagiwara S, Byerley L (1981) Calcium channels. Annu Rev Neurosci $4: 69-125$.

Harris EW, Ganong AH, Cotman CW (1984) Long-term potentiation in the hippocampus involves activation of $N$-methyl-D-aspartate receptors. Brain Res 323:132-137.

Hebb DO (1949) The organization of hehavior. New York: Wiley.

Izumi Y, Ito K, Miyakawa H, Kato H (1987) Requirement of extracellular $\mathrm{Ca}^{++}$after tetanus for induction of long-term potentiation in guinea pig hippocampal slices. Neurosci Lett 77:176-180.

Jaffe DB, Johnston D (1989) Voltage-dependence of LTP at the hippocampal mossy fiber synapse. Soc Neurosci Abstr 15:399.

Jia M, Nelson PG (1986) Calcium currents and transmitter output in cultured spinal cord and dorsal root ganglion neurons. J Neurophysiol 56:1257-1267.

Kelso SR, Ganong AA, Brown TH (1986) Hebbian synapses in the hippocampus. Proc Natl Acad Sci USA 83:5326-5330.

King AE, Cherubini C, Ben-Ari Y (1989) $N$-methyl-D-aspartate induces recurrent synchronization burst activity in immature hippocampal CA3 neurones in vitro. Dev Brain Res 46:1-8.

Kleinschmidt A, Bear M, Singer W (1987) Blockade of 'NMDA' receptors disrupts experience dependent plasticity of kitten striate cortex. Science 238:355-358.

Larson J, Lynch G (1988) Role of $N$-methyl-D-aspartate receptors in the induction of synaptic potentiation by burst stimulation patterned after the hippocampal theta rhythm. Brain Res 441:111-118.

Le Vay S, Wiesel TN, Hubel DH (1980) The development of ocular dominance columns in normal and visually deprived monkeys. J Comp Neurol 191:1-51.

Llinas R (1988) The intrinsic electrophysiological properties of mammalian neurons: insights into central nervous system function. Science 242:1654-1664.

Lynch G, Baudry M (1984) The biochemistry of memory: a new and specific hypothesis. Science 224:1057-1063.

Lynch G, Larson J, Kelso S, Barrionuevo G, Schottler F (1983) Intracellular injections of EGTA block the induction of hippocampal long-term potentiation. Nature 305:719-721.

MacDermott AB, Maycr ML, Westbrook GL, Smith SJ, and Barker JL (1986) NMDA-receptor activation increases cytoplasmic calcium concentration in cultured spinal cord neurones. Nature 321:519-522.

Magchielse T, Meeter E (1986) The effect of neuronal activity on the competitive elimination of neuromuscular junctions in tissue culture. Dev Brain Res 25:211-220.

Malenka RC, Kauer JA, Zucker RS, Nicoll RA (1988) Postsynaptic calcium is sufficient for potentiation of hippocampal synaptic transmission. Science 242:81-84.

Malinow R, Miller JP (1986) Postsynaptic hyperpolarization during conditioning reversibly blocks induction of long-term potentiation. Nature 320:529-530.

Martin KAC, Ramachandran VS, Rao VM, Whitteridge D (1979) Changes in ocular dominance induced in monocularly deprived lambs by stimulation with rotating gratings. Nature 277:391-393.

Mayer ML, Westbrook GL (1987) The physiology of excitatory amino acids in the vertebrate central nervous system. Proc Neurobiol 28: 197-276.

Mayer MM, MacDermott AB, Westbrook GL, Smith SJ, Barker JL (1987) Agonist- and voltage-gated calcium entry in cultured mouse spinal cord neurons under voltage clamp measured using arsenazo III. J Neurosci 7:3230-3244.

Miller KD, Chapman B, Stryker MP (1989) Visual responses in adult 
cat visual cortex depend on $N$-methyl-D-aspartate receptors. Proc Natl Acad Sci USA 86:5183-5187.

Miller RJ (1987) Multiple calcium channels and neuronal function. Science 235:46-52.

Mody I, Baimbridge KG, Miller JJ (1984) Blockade of tetanic- and calcium-induced long-term potentiation in the hippocampal slice preparation by neuroleptics. Neuropharmacology 23:625-631.

Morris RGM, Anderson E, Lynch GS, Baudry M (1986) Selective impairment of learning and blockade of long-term potentiation by an $N$-methyl-D-aspartate receptor antagonist, AP5. Nature 319:774-776.

Muller D, Joly M, Lynch G (1988) Contributions of quisqualate and NMDA receptors to the induction and expression of LTP. Science 242:1694-1697.

Neale EA, Fitzgerald SC, Bowers LM, Yu C, Fields RD, Nelson PG (1990) Multicompartment cell cultures for studies of neuronal interactions. In: Methods in neuroscience, vol 4 (Conn PM, ed). San Diego: Academic Press, in press.

Nelson PG, Marshall KC, Pun RYK, Christian CN, Sheriff WH Jr, Mac donald RL, Neale EA (1983) Synaptic interactions between mammalian central neurons in cell culture. II. Quantal analysis of EPSPs. J Neurophysiol 49:1442-1458.

Nelson PG, Yu C. Fields RD, Neale EA (1989a) Synaptic connections in vitro: modulation of number and efficacy by electrical activity. Science 244:585-587.

Nelson PG, Yu C, Fields RD, Brenneman D (1989b) NMDA receptors and calcium involvement in synapse elimination. Soc Neurosci Abstr 15:127.

Nelson PG, Fields RD, Yu C, Neale EA (1990) Mechanisms involved in activity-dependent synapse formation in mammalian central nervous system cell cultures. J Neurobiol 21:138-156.

Nicoletti F, Meek JL, Iadarola MJ, Chuang DM, Roth BL, Costa E (1986) Coupling of inositol phospholipid metabolism with excitatory amino acid recognition sites in rat hippocampus. J Neurochem 46: 40-46.

Nicoll RA, Kauer JA, Malenka RC (1988) The current excitement in long-term potentiation. Neuron 1:97-103.

O'Brien RAD, Ostberg AJC, Vrbová G (1984) Protease inhibitors reduce the loss of nerve terminals induced by activity and calcium in developing rat soleus muscle in vitro. Neuroscience 12:637-646.

Rauschecker JP, Singer W (1981) The effects of early visual experience on the cat's visual cortex and their possible explanation by Hebb synapscs. J Physiol (Lond) 310:215-239.

Redfern PA (1970) Neuromuscular transmission in newborn rats. J Physiol (Lond) 209:701-709.

Reiter HO, Stryker MP (1988) Neural plasticity without postsynaptic action potentials: less-active inputs become dominant when kitten visual cortical cells are pharmacologically inhibited. Proc Natl Acad Sci USA 85:3623-3627.

Reymann KG, Matthies HK, Frey U, Vorobyev VS, Matthies H (1986) Calcium-induced long-term potentiation in the hippocampal slice: characteristics of the time course and conditions. Brain Res Bull 17: 291-296.

Scherer WJ, Udin SB (1989) $N$-methyl-D-aspartate antagonists prevent interaction of binocular maps in Xenopus tectum. J Neurosci 9: $3837-3843$.

Schmidt JT (1990) Long-term potentiation and activity-dependent retinotopic sharpening in the regenerating retinotectal projection of goldfish: common sensitive period and sensitivity to NMDA blockers. J Neurosci 10:233-246.
Schmidt JT, Edwards DL (1983) Activity sharpens the map during the regeneration of the retinotectal projection in goldfish. Brain Res 269:29-39.

Simon R, Baudry M, Lynch GS (1987) Calcium-activated proteases as possible mediators of synaptic plasticity. In: Synaptic function (Edelman GM, Gall WE, Cowan WM, eds), pp 519-548. New York: Wiley.

Stanfield PR (1986) Voltage-dependent calcium channels of excitable membranes. Br Med Bull 42:359-367.

Stent GS (1973) A physiological mechanism for Hebb's postulate of learning. Proc Natl Acad Sci USA 70:997-1001.

Stryker MP, Harris WA (1986) Binocular impulse blockade prevents the formation of ocular dominance columns in cat visual cortex. J Neurosci 6:2117-2133.

Sugiyama H, Ito I, Hirono C (1987) A new type of glutamate receptor linked to inositol phospholipid metabolism. Nature 325:531-533.

Swanson GJ, Vrbová G (1987) Effects of low calcium and inhibition of calcium-activated neural protease (CANP) on mature nerve terminal structure in the rat sternocostalis muscle. Dev Brain Res 33: 199-203.

Thompson W (1983) Synapse elimination in neonatal rat muscle is sensitive to pattern of muscle use. Nature 302:614-616.

Tsumoto T, Hagihara K, Sato H, Hata Y (1987) NMDA receptors in the visual cortex of young kittens are more effective than those of adult cats. Nature 327:513-514.

Turner RW, Baimbridge KG, Miller JJ (1982) Calcium-induced longterm potentiation in the hippocampus. Neuroscience 7:1411-1416.

Watkins JC, Evans RH (1981) Excitatory amino acid transmitters. Annu Rev Pharmacol Toxicol 21:165-204.

Wickens J (1988) Electrically coupled but chemically isolated synapses: dendritic spines and calcium in a rule for synaptic modification. Prog Neurobiol 31:507-528.

Wiesel TN, Hubel DH (1963) Single-cell responses in striate cortex of kittens deprived of vision in one eye. J Neurophysiol 26:10031017.

Wiesel TN, Hubel DH (1965) Comparison of the effects of unilateral and bilateral eye closure on cortical unit responses in kittens. J Neurophysiol 28:1029-1040.

Wigstrom H, Gustafsson B (1985) On long-lasting potentiation in the hippocampus: a proposed mechanism for its dependence on coincident pre- and postsynaptic activity. Acta Physiol Scand 105:126-128.

Wigstrom H, Swan JW, Andersen P (1979) Calcium dependency of synaptic long lasting potentiation in the hippocampal slice. Acta Physiol Scand 105:126-128.

Wigstrom H, Gustafsson B, Huang Y-Y, Abraham WC (1986) Hippocampal long-term potentiation is induced by pairing single afferent volleys with intracellularly injected depolarizing current pulses. Acta Physiol Scand 126:317-319.

Williams SH, Johnston D (1989) Hippocampal CA3 mossy fiber LTP is blocked by postsynaptic calcium chelators. Soc Neurosci Abstr 15: 399.

Winer BJ (1971) Statistical principles in experimental design, 2d ed. New York: McGraw-Hill.

Ziskind-Conhaim L (1990) NMDA receptors mediate poly- and monosynaptic potentials in motor neurons of rat embryos. J Neurosci $10: 125-135$. 